\title{
Long-term Prognosis of Patients Who Contraindicated for Intravenous Thrombolysis in Acute Ischemic Stroke
}

\author{
Bo-Yeon Lee ${ }^{1}$, Jae-Sang Oh², Seok-Mann Yoon² \\ 'Department of Public Health, Graduate school of Korea University, Seoul, South Korea ; 'Department of Neurosurgery, \\ College of Medicine, Soonchunhyang University, Cheonnan Hospital, South Korea
}

Background : As intravenous thrombolysis (IVT) has very restricted inclusion criteria, eligible patients of IVT constitute a very small proportion and studies about their mortality are rare. The long-term mortality in a patients with contraindication of ineligible patients of IVT still under the debate. So, we investigated the proportion of patients with contraindication of IVT and the short and long-term mortality of them in AIS on emergency department comparing with the long-term effect of IVT in patients with moderate-to-severe stroke.

Methods : Using acute stroke assessment indication registry \& Health Insurance Review and Assessment Service database, a total of 5,407 patients with NIHSS $\geq 5$ were selected from a total of 169 acute stroke care hospital nationwide during October-December 2011 and March-June 2013. We divided AIS patients into two groups: 1) IVT group who received IVT within 4.5 hours, and 2) non-IVT group who did not receive the IVT because of contraindications. And we divided the subgroups according to the reason of contraindication of IVT. The 5-year survival rate of each group was assessed using Kaplan-Meyer survival analysis.

Results : Of the 5,407 patients, a total of 1,027 (19\%) patients who received IVT using r-tPA within $4.5 \mathrm{~h}$ after onset. Compared with the IVT group, hazard ratios of non-IVT group were 1.33 at 3 months, 1.53 at 1 year and 1.47 at 5 years $(p<.001)$. A total of 4,380 patients did not receive IVT because of the following contraindications to IVT. 1) Time restriction: 3,378 (77.1 \%) patients were admitted after $4.5 \mathrm{~h}$ following stroke onset, and 144 (3.3\%) patients failed to determine the stroke onset time. 2) Mild symptoms:137 (3.1\%) patients had rapid improvement or mild stroke on emergency room, 3) Bleeding diathesis or non-adjustable hypertension: 53 (1.2\%) patients showed a bleeding tendency or severe hypertension. Compared with the IVT group, the subgroups of non-IVT group showed consistently high mortality during short and long term follow up. Mild symptom and bleeding diathesis or non-adjustable hypertension subgroup in the non-IVT group consistently showed the higher mortality than time restriction subgroup during the short and long-term follow-up (log-rank $p<.001$ ). Patients who had rapid improvement or mild stroke on emergency department had the higher mortality than time restriction group in short and long term follow up.

Conclusion : The AIS patients with rapid improvement or mild stroke on emergency room had higher mortality than ineligible patients of IVT due to time restriction during the short and long-term follow-up. A further management and special support on emergency department is needed for these patients with initially mild stroke and rapid improvement in AIS to reduce the poor outcome.

Keywords Stroke, Thrombolytic Therapy, Tissue Plasminogen Activator, Mechanical Thrombectomy, Mortality, Emergency Medical Services
J Cerebrovasc Endovasc Neurosurg. 2019 June;21(2):77-85

Received : 24 May 2019

Revised : 20 June 2019

Accepted : 26 June 2019

Correspondence to Jae-Sang Oh Department of Neurosurgery, College of Medicine, Soonchunhyang University, Cheonnan Hospital, South Korea

Tel : 041-570-2180

Fax : +8241-572-9297

E-mail : metatron1324@hotmail.com

ORCID : http://orcid.org/0000-0003-4570-6763
This is an Open Access article distributed under the terms of the Creative Commons Attribution NonCommercial License /http://creativecommons.org/licenses/by-nc/3.0) which permits unrestricted noncommercial use, distribution, and reproduction in any medium, provided the original work is properly cited. 


\section{INTRODUCTION}

Intravenous thrombolysis (IVT) using recombinant tissue plasminogen activator ( $\mathrm{r}-\mathrm{tPA}$ ) is a primary treatment for acute ischemic stroke (AIS). It is associated with improved functional outcome at 3 months. However, it is still debated whether IVT reduces the mortality or improved the functional outcome during long-term follow-up. In addition, most large randomized controlled studies had investigated with a limited period until 3 or 12 months. ${ }^{16)}$ Although the Third International Study of Stroke (IST-3) analyzed the efficacy of IVT on functional outcomes for 18 months, this study failed to reduce the mortality at 18-month follow-up. ${ }^{17}$

Despite large-scale international observational studies over the past 20 years demonstrating the benefit of IVT using r-tPA as a standard treatment for AIS, the indications for IVT remain unchanged since the National Institute of Neurological Disorder and Stroke (NINDS) trial. ${ }^{18)}$ As IVT has very restricted inclusion criteria and has a narrow time window, small proportion of patients are eligible for IVT. Mechanical thrombectomy become a main treatment for AIS since positive results of many randomized control study. Therefore, re-establishment of indication or contraindication of IVT is needed after studying the prognosis of patients who failed to receive IVT following AIS.

Previous studies were limited in representing general population because they were performed at expert stroke centers with well-designed protocols. Clinical trial results should be generalized to patients treated in routine clinical practice, which also needs to be confirmed during long-term follow-up in general population. Due to these limitations of previous studies, the influence of IVT should be investigated to determine the absolute and relative contraindications for the procedure. Since most of these studies presented short-term outcomes (within 6 months), long-term studies of IVT in large-sized samples are needed.
We investigated the differences in long-term prognosis between patients who received IVT and those who did not due to contraindications. To assess the differences in mortality based on the contraindications, we studied the short and long-term mortality of each AIS patient who was admitted to emergency rooms. Using Health Insurance Review \& Assessment Service (HIRA) database and acute stroke assessment indication data, we collected the data of patients with AIS who were admitted to 169 hospitals involving 100 beds during 2011 until 2013. These data included all patients who were admitted for AIS within 7 days after symptom onset. The data involve patients enrolled with acute stroke assessment indication registry at almost all the acute stroke care hospitals in Korea to assess the quality of acute stroke care. Therefore, these data are very reliable and represent the results of long-term follow-up.

\section{Subjects and methods}

\subsection{Data source}

Government of Korea have a policy with national health insurance to improve the health and reduce the mortality of people. Acute stroke assessment indication registry is also one of representative policy including most stroke care hospitals nationwide. This registry is that HIRA has estimated the quality of management for AIS patients during a 3-month period each year since 2007. Data for this study were obtained and all AIS cases were analyzed from the NHI claims database linked with the HIRA database during October-December 2011 and March-June 2013.

We defined as an AIS patient who was diagnosed with ischemic stroke (ICD-10:163) as the first-onset stroke and was admitted via emergency room during the study period. A total of 5,407 patients above the age of 18 years were selected from a total of 169 medical institutions. Enrolled hospitals were randomly selected from the hospitals with at least 100 beds and more than 10 AIS patients per year. We collected clinical data and medical records of AIS patients sent automatically to HIRA. And we collected data about the 
mortality of selected patients using both the administrative data and HIRA. So, these data are regarded as very highly reliable and accurate for study about the long term mortality.

\subsection{Study population and grouping}

A total of 24,469 inpatients were admitted via emergency room in 2011 (October to December) and 2013 (March to June). Of these, 14,658 of AIS patients (Tenth International Classification of Diseases: I63) were admitted within 7 days of symptom onset. Patients over the age of 18 years and with $>5$ NIHSS score (moderate or severe acute ischemic stroke) on onset of stroke who were not hospitalized for an ischemic stroke or related illnesses in the past year, were included in the study. The reason why mild AIS patients (NIHSS 0 5) were excluded is that patients for active management using IVT had indication with $>5$ NIHSS score for treatment of AIS at the period (from 2011 to 2013) in Korea. So, we excluded the patients with low NIHSS $(\leq 5)$ at emergency department because they are possible to have a transient ischemic attack or misdiagnosis of acute ischemic stroke. These patients are prone to exclude the IVT regarding as high chance of development of the hemorrhagic complication in acute ischemic stroke before endovascular thrombectomy era (2015).

A total of 5,407 patients were selected as subjects finally. We divided AIS patients into two groups: 1) IVT group including patients who received IVT within $4.5 \mathrm{~h}$ after symptom onset, and 2) non-IVT group including patients who did not receive IVT because of contraindication to IVT. According to reason of contraindication of IVT, non-IVT group were divided into 4 subgroups; 1$)$ time restriction: delayed arrival time $>4.5 \mathrm{~h}$ after stroke onset or unknown onset time, 2) Mild symptoms: rapid improvement or mild stroke on emergency department, 3) Bleeding diathesis or non-adjustable hypertension: platelet $<100,000$, active Partial Thromboplastin Time (aPTT) $>40 \mathrm{~s}$, International Normalized Ratio (INR) $>1.7$ or non-adjusted hypertension (systolic blood pressure $180 \mathrm{mmHg}$ ), 4) others (intracranial hemorrhage or treatment refusal).

\subsection{Measurement of Variables}

Patient-related factors included age, sex, type of health insurance, medical history (atrial fibrillation, smoker), Charlson Comorbidity Index, stroke severity (National Institutes of Health Stroke Scale, NHISS), arrival time, arrival mode (EMS, private vehicle), stroke onset time (last normal time, first abnormal time), and medications prior to admission. Hospital-related factors included medical facility type, hospital location, number of beds, and the presence of stroke unit. Intervention-related factors including the door-to-image time, initiation time of tPA treatment (onset-to-needle time, door-to-injection time), tPA complications, mechanical thrombectomy, and in-hospital mortality were collected by well-trained hospital researchers. Stroke severity was measured according to the NIHSS.

\subsection{Statistical analysis}

Patient demographics, clinical variables and clinical outcomes were compared between the 2 groups (one IVT group and four non-IVT groups). Percentages and mean standard deviations or median interquartile ranges (IQRs) were reported for categorical and continuous variables, respectively. The Pearson $x^{2}$ test and Wilcoxon rank-sum tests were used to compare the categorical and continuous variables, respectively. Multivariable Cox regression analyses were performed to explore the relationship between the use of IVT and clinical outcome, including (1) mortality at 3 months, (2) mortality at 1 year, and (3) mortality at 5 years adjusted for patient-, hospital-, and intervention-related factors. All $\mathrm{P}$ values were 2 -sided and statistical significance was defined as $\mathrm{P}<.05$. The survival rate in the non-IVT group was evaluated according to subgroups and the reason for contraindication of IVT during 5 years using Kaplan-Meyer survival analysis. The Kaplan-Meyer survival analyses were performed using SAS (9.4) software (SAS institute, Cary, NC, USA). 


\section{RESULTS}

\subsection{Baseline characteristics}

Of the 5,407 patients, $51.7 \%$ were male and the mean age was $71.3 \pm 12.2$ years. A total of $1,027(19 \%)$ patients who received IVT using r-tPA within $4.5 \mathrm{~h}$ after onset, and 460 (8.5\%) patients received MT. Among 809 (15\%) who received only tPA, 218 (4\%) received MT after tPA, and $242(4.5 \%)$ only received MT after $4.5 \mathrm{~h}$. The proportion of patients with an onset-to-door time (OTD) $\leq 2 \mathrm{~h}$ were approximately 1446 $(26.7 \%)$, of whom 923 (89.9\%) received IVT. A total of $4,871(90.1 \%)$ patients underwent imaging within 1 hour (door-to-image time $\leq 1 \mathrm{hr}$ ); 1,729 (33.2\%) patients had accompanying arterial fibrillation, and 3,709 (68.6\%) patients arrived via EMS. The average NIHSS of patients who received IVT was higher than patients who did not receive IVT. All baseline characteristics are summarized in Table 1. Mean follow up period was 4.5 years (range 3.6-5.3 years).

\subsection{Contraindications to IVT}

A total of 4,380 patients did not receive IVT because of the following contraindications to IVT. 1) Time restriction: 3,378 (77.1\%) patients were admitted after $4.5 \mathrm{~h}$ following stroke onset, and 144 (3.3\%) patients failed to determine the stroke onset time. 2) Mild symptoms:137 (3.1\%) patients had rapid improvement or mild stroke on emergency room, 3) Bleeding diathesis or non-adjustable hypertension: 53 (1.2\%) patients showed a bleeding tendency or severe hypertension, and 4) Others: abnormal ICH or SAH upon initial imaging or treatment refusal occurred in 111 $(2.5 \%)$ patients. The reasons of non-IVT group are summarized in Table 2.

\subsection{Analysis of factors influencing mortality}

Compared with the IVT group, the 3-month HR of non-IVT group were 1.33, and HR was 1.53 and 1.47 at 1 year and 5 year, respectively $(p<.001)$. The group that did not receive MT showed higher 3-month, 1and 5-year HRs of 1.40, 1.36, and 1.28, respectively $(\mathrm{p}<.01)$. Among factors influencing long-term mortal- ity, patients aged $\geq 70$ years had a higher HR compared with patients $\leq 45$ years of age $(p<.01)$. Patients with high NIHSS 22-42 showed a higher HR and in particular, compared with patients with a score ranging from 5 to $7(p<.001)$. The HR of the EMS group was higher than that of the non-EMS group. The HR of patients with accompanying arterial fibrillation was higher than those without arterial fibrillation $(p<.001)$. The medical aid group had higher HR than the health insurance group $(p<.001)$. Factors influencing the short and long-term mortality on AIS are summarized in Table 3.

\subsection{Survival rates of IVT and non-IVT groups during long-term follow-up}

Compared with the IVT group, both time-restricted and mild symptom subgroups in the non-IVT group manifested a lower survival rate during 5 years. Bleeding diathesis or non-adjustable hypertension subgroup had the lowest survival rate during long-term follow-up (log-rank $p<.001$ ). Interestingly, we could fine the IVT group as well as each group consistently affect not only the short-term, but also the long-term prognosis in patients of AIS (Fig 1).

\section{DISCUSSION}

Our result showed the current status of acute stroke management in Korea and the long term mortality according to acute management on emergency department using very reliable data of HIRA and acute stroke assessment indication registry. Using reliable and valid data in stroke registry and information collected by HIRA, we showed that the rate of IVT in AIS was also low at 19\% despite good medical and hospital access in Korea. In addition, the long-term mortality of non-IVT group was higher than in IVT group. Especially, the two subgroups with mild symptoms and bleeding diathesis or non-adjustable hypertension as contraindications to IVT showed very high mortality consistently during short and longterm follow-up. This result may suggest that contra- 
indications to IVT should be revised or indications for IVT should be broadened to reduce the poor out- comes in AIS. A few studies also reported that minor contraindications to IVT are not dangerous and rela-

Table 1. Baseline characteristics of acute ischemic stroke

\begin{tabular}{|c|c|c|c|c|}
\hline \multirow{2}{*}{ Variables, N (\%) } & Total & IVT & Non-IVT & $P$ \\
\hline & $n=5,407$ & $n=1,027$ & $n=4,380$ & Value \\
\hline $\begin{array}{l}\text { Patient level } \\
\text { Age, mean (SD), y } \\
\text { 18-45 } \\
46-59 \\
46-69 \\
\geq 70\end{array}$ & $\begin{aligned} 71.3 & (12.2) \\
161 & (3.0) \\
770 & (14.2) \\
1,079 & (20.0) \\
3,397 & (62.8)\end{aligned}$ & $\begin{aligned} 68.1 & (12.4) \\
52 & (5.1) \\
191 & (18.6) \\
234 & (22.8) \\
550 & (53.6)\end{aligned}$ & $\begin{aligned} 72.1 & (12.0) \\
109 & (2.5) \\
579 & (13.2) \\
845 & (19.3) \\
2,847 & (65.0)\end{aligned}$ & $\begin{array}{l}<.01 \\
<.01\end{array}$ \\
\hline $\begin{array}{l}\text { Male, sex } \\
\text { Female, sex }\end{array}$ & $\begin{array}{l}2,873(53.1) \\
2,534(46.9)\end{array}$ & $\begin{array}{l}610(59.4) \\
417(40.6)\end{array}$ & $\begin{array}{l}2,263(51.7) \\
2,117(48.3)\end{array}$ & $<.01$ \\
\hline $\begin{array}{l}\text { Health insurance type } \\
\text { Health insurance } \\
\text { Medical aid }\end{array}$ & $\begin{array}{r}4,925(91.1) \\
482(8.9)\end{array}$ & $\begin{aligned} 959 & (93.4) \\
68 & (6.6)\end{aligned}$ & $\begin{array}{c}3,966(90.6) \\
414(9.5)\end{array}$ & 0.01 \\
\hline $\begin{array}{l}\text { NIHSS, mean (SD), score } \\
5-7 \\
8-13 \\
14-21 \\
22-42\end{array}$ & $\begin{aligned} 11.5 & (6.3) \\
2,017 & (37.3) \\
1,634 & (30.2) \\
1,319 & (24.4) \\
437 & (8.1)\end{aligned}$ & $\begin{aligned} 12.4 & (6.0) \\
276 & (26.9) \\
340 & (33.1) \\
327 & (31.8) \\
84 & (8.2)\end{aligned}$ & $\begin{array}{c}11.2(6.4) \\
1,741(39.8) \\
1,294(29.5) \\
992(22.7) \\
353(8.1)\end{array}$ & $\begin{array}{l}<01 \\
<.01\end{array}$ \\
\hline $\begin{array}{l}\text { Medical history } \\
\text { Smoker } \\
\text { Atrial fibrillation/flutter } \\
\text { Intracranial hemorrhage } \\
\text { Seizure }\end{array}$ & $\begin{aligned} 2,123 & (39.3) \\
1,797 & (33.2) \\
96 & (1.8) \\
53 & (1.0)\end{aligned}$ & $\begin{aligned} 430 & (41.9) \\
429 & (41.8) \\
23 & (2.2) \\
6 & (0.6)\end{aligned}$ & $\begin{aligned} 1,693 & (38.7) \\
1,368 & (31.2) \\
73 & (1.7) \\
47 & (1.1)\end{aligned}$ & $\begin{array}{l}0.16 \\
<.01 \\
0.24 \\
0.36\end{array}$ \\
\hline $\begin{array}{l}\mathrm{CCl} \text {, score } \\
0 \\
1 \\
2 \\
\geq 3\end{array}$ & $\begin{aligned} 829 & (15.3) \\
1,503 & (27.8) \\
810 & (15) \\
2,265 & (41.9)\end{aligned}$ & $\begin{array}{ll}129 & (12.6) \\
286 & (27.8) \\
156 & (15.2) \\
456 & (44.4)\end{array}$ & $\begin{array}{r}700(16.0) \\
1,217(27.8) \\
654(14.9) \\
1,809(41.3)\end{array}$ & $<.01$ \\
\hline $\begin{array}{l}\text { Assessment level } \\
\text { Onset to door time } \\
\leq 2 \mathrm{hr} \\
>2 \mathrm{hr} \\
\text { Unknown }\end{array}$ & $\begin{array}{c}1,443(26.7) \\
3,820(70.7) \\
144(2.7)\end{array}$ & $\begin{array}{l}923(89.9) \\
104(10.1)\end{array}$ & $\begin{array}{c}520(11.9) \\
3,716(84.8) \\
144(3.3)\end{array}$ & $<.01$ \\
\hline Mechanical thrombectomy & $460(8.5)$ & $218(21.2)$ & $242(5.5)$ & $<.01$ \\
\hline $\begin{array}{l}\text { Arrival mode } \\
\text { EMS } \\
\text { No EMS }\end{array}$ & $\begin{array}{l}3,709(68.6) \\
1,698(31.4)\end{array}$ & $\begin{array}{l}804(78.3) \\
223 \text { (21.7) }\end{array}$ & $\begin{array}{l}2,905(66.3) \\
1,475(33.7)\end{array}$ & $<.01$ \\
\hline $\begin{array}{l}\text { Door to image time } \\
\leq 1 \mathrm{hr} \\
>1 \mathrm{hr}\end{array}$ & $\begin{aligned} 4,871 & (90.1) \\
536 & (9.9)\end{aligned}$ & $\begin{aligned} 1,020 & (99.3) \\
7 & (0.7)\end{aligned}$ & $\begin{array}{r}3,851(87.9) \\
529(12.1)\end{array}$ & $<.01$ \\
\hline $\begin{array}{l}\text { Hospital level } \\
\text { Medical facility type } \\
\text { Tertiary general hospital } \\
\text { General hospital }\end{array}$ & $\begin{array}{l}3,026(56) \\
2,381(44)\end{array}$ & $\begin{array}{l}615(59.9) \\
412(40.1)\end{array}$ & $\begin{array}{ll}2,411 & (55.1) \\
1,969 & (45.0)\end{array}$ & 0.01 \\
\hline $\begin{array}{l}\text { Hospital location } \\
\text { urban } \\
\text { rural }\end{array}$ & $\begin{array}{l}3,279(60.6) \\
2,128(39.4)\end{array}$ & $\begin{array}{l}613(59.7) \\
414(40.3)\end{array}$ & $\begin{array}{l}2,666(60.9) \\
1,714(39.1)\end{array}$ & 0.49 \\
\hline $\begin{array}{l}\text { No. of beds } \\
\leq 500 \\
>500\end{array}$ & $\begin{array}{l}1,054(19.5) \\
4,353(80.5)\end{array}$ & $\begin{array}{l}176(17.1) \\
851 \quad(82.9)\end{array}$ & $\begin{array}{r}878(20.1) \\
3,502(80.0)\end{array}$ & 0.03 \\
\hline $\begin{array}{l}\text { Stroke unit } \\
\text { yes } \\
\text { no }\end{array}$ & $\begin{array}{l}3,103(57.4) \\
2,304(42.6)\end{array}$ & $\begin{array}{l}597(58.1) \\
430(41.9)\end{array}$ & $\begin{array}{l}2,506(57.2) \\
1,874(42.8)\end{array}$ & 0.59 \\
\hline $\begin{array}{l}\text { No. of death, } \mathrm{n}(\%) \\
\text { 3-month } \\
\text { 1-year } \\
\text { 5-year }\end{array}$ & $\begin{array}{r}764(14.1) \\
1,094(20.3) \\
1,759(32.5)\end{array}$ & $\begin{array}{ll}128 & (12.5) \\
163 & (15.9) \\
271 & (26.4)\end{array}$ & $\begin{aligned} 636 & (14.5) \\
931 & (21.3) \\
1,488 & (34.0)\end{aligned}$ & $\begin{array}{l}0.09 \\
<.01 \\
<.01\end{array}$ \\
\hline
\end{tabular}

* Note: SD=standard deviation, IVT= Intravenous thrombolysis, NIHSS=national Institutes of Health Stroke Scale, CCl=charlson's comorbidity index, EMS=emergency medical services. 
Table 2. The reason that intravenous tissue plasminogen activator (tPA) did not be treated

\begin{tabular}{|c|c|c|}
\hline Category & $\mathrm{N}(\%)$ & OTD, median, mins \\
\hline $\begin{array}{l}\text { Contraindications ( } \mathrm{n}=3,686 \text { ) } \\
\text { Treated }>4.5 \mathrm{hr} \text { after stroke onset } \\
\text { Unknown onset time } \\
\text { Non-adjustable hypertension } \\
\text { Bleeding diathesis (Platelets } \leq 100,000 \text {, abnormal aPTT, INR } \geq 1.5 \text { ) } \\
\text { CT findings for ICH, SAH }\end{array}$ & $\begin{aligned} 3,378 & (77.1) \\
144 & (3.3) \\
13 & (0.3) \\
40 & (0.9) \\
111 & (2.5)\end{aligned}$ & $\begin{array}{l}422 \\
- \\
118 \\
61 \\
62\end{array}$ \\
\hline $\begin{array}{l}\text { Warnings ( } \mathrm{n}=508 \text { ) } \\
\text { Not treated with intravenous tPA(no reason) } \\
\text { Rapid improvement or mild stroke } \\
\text { Eligibility not clear }\end{array}$ & $\begin{aligned} 351 & (8.0) \\
137 & (3.1) \\
20 & (0.5)\end{aligned}$ & $\begin{array}{l}62 \\
61 \\
62\end{array}$ \\
\hline $\begin{array}{l}\text { Others }(n=186) \\
\text { Patient or family refusal } \\
\text { Received intravenous tPA at another hospital }\end{array}$ & $\begin{array}{r}63(1.4) \\
123(2.8)\end{array}$ & $\begin{array}{c}60 \\
240\end{array}$ \\
\hline
\end{tabular}

Table 3. Cox analysis of factors influencing mortality in acute ischemic stroke

\begin{tabular}{|c|c|c|c|}
\hline Variables/refl & 3-month & 1-year & 5-year \\
\hline 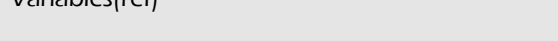 & HR $(95 \% \mathrm{Cl})$ & $\mathrm{HR}(95 \% \mathrm{CI})$ & HR $(95 \% \mathrm{CI})$ \\
\hline $\begin{array}{l}\text { Onset to treatment time(IVT) } \\
\text { Non-IVT }\end{array}$ & $1.33(1.09-1.62)$ & $1.53(1.28-1.81)$ & 1.47 (1.28-1.68) \\
\hline $\begin{array}{l}\text { Mechanical Thrombectomy(Yes) } \\
\text { No }\end{array}$ & $1.40(1.09-1.80)$ & $1.36(1.09-1.69)$ & $1.28(1.08-1.53)$ \\
\hline $\begin{array}{l}\text { Age(18-45y) } \\
46-59 y \\
46-69 y \\
\geq 70 y\end{array}$ & $\begin{array}{l}2.78(0.87-8.94) \\
3.47(1.10-10.95) \\
4.13(1.32-12.89)\end{array}$ & $\begin{array}{l}2.85(1.04-7.83) \\
4.08(1.51-11.01) \\
5.89(2.20-15.76)\end{array}$ & $\begin{array}{ll}2.71 & (1.26-5.84) \\
4.59 & (2.17-9.73) \\
7.59 & (3.61-15.98)\end{array}$ \\
\hline Female, sex & $0.98(0.83-1.17)$ & $0.90(0.78-1.03)$ & $0.87(0.78-0.97)$ \\
\hline $\begin{array}{l}\text { Health insurance type(Health insurance) } \\
\text { Medical aid }\end{array}$ & 1.45 (1.17-1.80) & $1.37(1.14-1.65)$ & $1.4(1.21-1.62)$ \\
\hline $\begin{array}{l}\text { Arrival mode(EMS) } \\
\text { No EMS }\end{array}$ & $0.67(0.54-0.83)$ & $0.72(0.61-0.85)$ & 0.77 (0.68-0.87) \\
\hline $\begin{array}{l}\text { NIHSS score(5-7) } \\
8-13 \\
14-21 \\
22-42\end{array}$ & $\begin{array}{l}2.08(1.56-2.77) \\
4.56(3.48-5.98) \\
9.77(7.36-12.98)\end{array}$ & $\begin{array}{ll}2.00 & (1.63-2.46) \\
3.57 & (2.92-4.37) \\
7.31 & (5.88-9.10)\end{array}$ & $\begin{array}{l}1.43(1.25-1.64) \\
2.25(1.95-2.58) \\
4.12(3.50-4.85)\end{array}$ \\
\hline $\begin{array}{l}\text { Door to image time }(\leq 1 \mathrm{hr}) \\
>1 \mathrm{hr}\end{array}$ & 1.41 (1.12-1.78) & $1.37(1.13-1.66)$ & $1.15(0.98-1.35)$ \\
\hline $\begin{array}{l}\text { Medical history } \\
\text { Smoker } \\
\text { Atrial fibrillation/flutter } \\
\text { Intracranial hemorrhage } \\
\text { Seizure }\end{array}$ & $\begin{array}{ll}1.06 & (0.88-1.27) \\
4.41 & (3.72-5.22) \\
1.23 & (0.79-1.90) \\
1.52 & (0.86-2.70)\end{array}$ & $\begin{array}{ll}1.03 & (0.88-1.19) \\
3.09 & (2.71-3.52) \\
1.21 & (0.82-1.78) \\
1.56 & (0.96-2.53)\end{array}$ & $\begin{array}{ll}0.98 & (0.87-1.11) \\
2.20 & (1.99-2.43) \\
1.24 & (0.91-1.70) \\
1.40 & (0.93-2.11)\end{array}$ \\
\hline $\begin{array}{l}\text { Charlson Comorbidity Index score(0) } \\
1 \\
2 \\
\geq 3\end{array}$ & $\begin{array}{l}1.10(0.86-1.41) \\
0.90(0.68-1.18) \\
1.09(0.86-1.37)\end{array}$ & $\begin{array}{l}1.17(0.95-1.43) \\
1.00(0.79-1.25) \\
1.15(0.94-1.39)\end{array}$ & $\begin{array}{l}1.27(1.08-1.49) \\
1.16(0.97-1.39) \\
1.24(1.06-1.44)\end{array}$ \\
\hline $\begin{array}{l}\text { Medical facility type(Tertiary general hospital) } \\
\text { General hospital }\end{array}$ & $1.24(1.08-1.44)$ & $1.16(1.03-1.31)$ & $1.15(1.04-1.26)$ \\
\hline
\end{tabular}

* Note : SD=standard deviation, HR=Harzard Ratio, IVT= Intravenous thrombolysis, NIHSS=national Institutes of Health Stroke Scale, $\mathrm{CCl}=$ charlson's comorbidity index, EMS=emergency medical services.

tively safe.

IVT using r-tPA became the standard of care for acute ischemic stroke presenting within the time win- dow since $1995 .{ }^{19)}$ In 2008, the limited time window was broadened to $4.5 \mathrm{~h}^{4}{ }^{4)}$ Although the safety and efficacy of IVT has been confirmed in many studies, the 


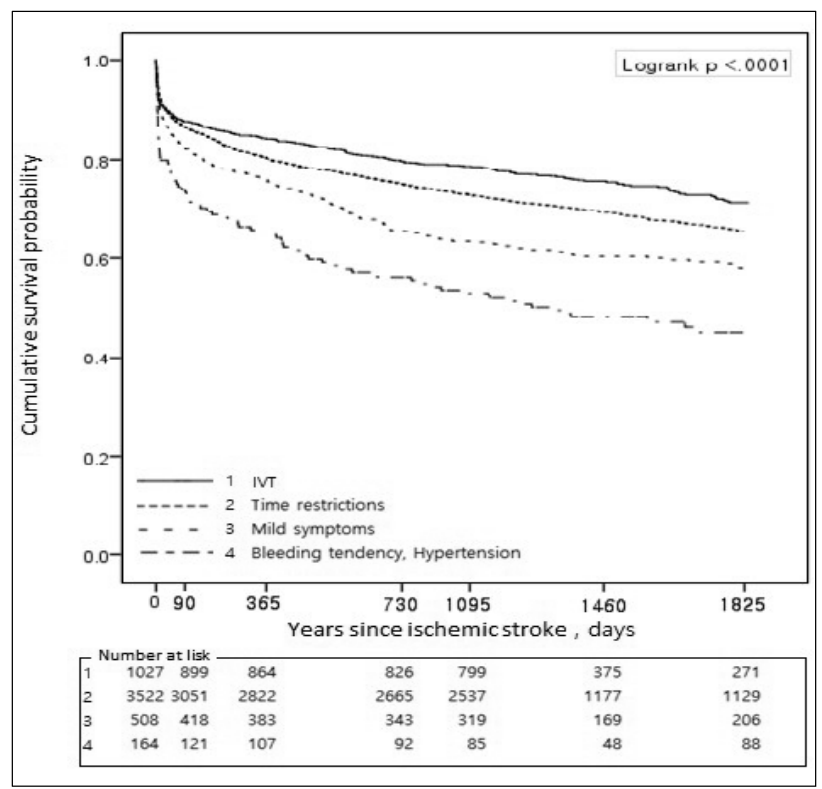

Fig. 1. The 5-year survival rate of acute ischemic stroke patients between IVT group and non-IVT group. IVT: Intravenous thrombolysis

rate of IVT is still below $20 \%$ because of strict indications for IVT. Since the contraindications of IVT were strictly derived from the consensus on National Institute of Neurological Disorders and Stroke (NINDS) trials, they have not changed over the past 20 years. However, some studies showed unnecessary contraindications of IVT in clinical practice, and the need for relaxing the exclusion criteria.

A few studies reported that $20 \%$ to $30 \%$ of patients with mild or improving symptoms under consideration for thrombolysis may be at risk of substantial disability at 3 months. ${ }^{6) 10) 11)}$ In fact, low NIHSS does not always represent minor deficits for the patient. Severe monoparesis, gait imbalance, aphasia, or severe visual field deficit may suggest disabling deficits in isolation; some patients with mild symptoms can have proximal intracranial vessel occlusion with good collateral status and are at greater risk of neurological deterioration and persistent disability. ${ }^{6) 13)}$ This current study showed that the patients with mild symptoms at emergency department have a very poor prognosis during short and long-term prognosis. It could be correlated with chronic extracranial or intracranial steno- sis, so that these patients should be carefully taken care or given the antithrombolytic drugs during long-term follow up.

Studies show that baseline BP is not an independent predictor of ICH or poor outcomes. ${ }^{14) 15)}$, and higher pretreatment systolic blood pressure was not independently associated with outcome. In patients undergoing IVT, no significant difference was found between those manifesting severe hypertension and sICH. ${ }^{5)}$ In addition, the use of antihypertensives to achieve stable blood pressure control in patients prior to r-tPA appears to be safe.

Despite a platelet count $<100000 / \mathrm{mm}^{3}$ being a contraindication for IVT for AIS according to AHA guidelines, hemorrhagic complications in patients with thrombocytopenia who receive IVT have yet to be evaluated in a prospective study or randomized trial. Large observational studies showed that warfarin-treated patients (INR >1.7) exposed to IVT manifested a very small rate of symptomatic intracranial hemorrhage. ${ }^{1-3) 78) 99}$. Other studies showed that patients who were treated with IVT compared with controls have a slightly favorable outcome, although this difference was not statistically significant. In addition, patients treated with direct oral anticoagulant or low-molecular weight heparin showing a lower bleeding tendency than warfarin have remained unidentified. In these specific issues, further studies are needed.

We found that the IVT consistently affected not only the short-term, but also the long-term prognosis in patients diagnosed with AIS. In addition, despite patients with MT representing a small number in this study, they also affected the short and long-term mortality. Active management in critical to improve the functional status and reduce the mortality rate. However, they are still limited by the narrow time window and indication. Recently published DAWN and DFFUSE trials represented an enlarged time window and broadened the indications for MT in the management of AIS. However, even these trials did not involve patients who failed to receive IVT and the 
indications for MT still remain for IVT except for the time window. Therefore, this result might show an overwhelming benefit of MT and failed to suggest that MT improved the prognosis of patients who did not receive IVT. Patients with large-vessel occlusion who present within the therapeutic time window at a medical center without endovascular capabilities, it is reasonable to use IVT promptly before transfer to the nearest endovascular therapy center. IVT still represents a potent treatment for AIS and its benefit for successful recanalization before MT was found in approximately 1 of 10 AIS patients. ${ }^{12)}$ Therefore, a further study investigating patients for contraindications to IVT should be conducted to reduce the mortality and improve the outcomes in AIS.

In the current study, the application rate of MT among the total AIS patients was very low at $8.5 \%$. MT was performed with $21.2 \%$ in IVT group and $5.5 \%$ in non-IVT group. These data were collected from 2010 and 2013 prior to the endovascular thrombectomy era and this period underestimated the mechanical thrombectomy using a stent retriever. Before 2014, the Solitaire stent retriever (Medtronic, Dublin, Ireland) was prohibited by the NHI system of Korea (National Health Insurance) during this period. The MT was conducted under restrictions for AIS patients who failed to obtain successful recanalization of the occluded vessel after IVT. Because IVT was the only standard guideline for treatment of AIS in this period, the difference in short and long-term prognosis between IVT group and the group contraindicated for IVT could be clearly distinguished.

\section{CONCLUSION}

The long-term prognosis of patients who failed to receive IVT was very poor. Especially, the two subgroups with mild symptoms and bleeding diathesis or non-adjustable hypertension as contraindications to IVT consistently showed very high mortality during short and long-term follow-up. Therefore, a further study to enlarge the indications of IVT or release the contraindications of IVT is needed to reduce the mortality in such patients diagnosed with AIS. In addition, a new strategy for MT in AIS should broaden to include patients contraindicated for IVT.

\section{Conflict of Interest}

There was no conflict of interest.

\section{ACKNOWLEDGEMENTS}

This research was supported by Soonchunhyang University Research Fund.

This research was supported by the Bio \& Medical Technol ogy Development Program of the National Research Foundation (NRF) funded by the Korean government (MSIT) (NRF-2017R1C1B5017801 \& NRF2019M3E5D1A02069061).

\section{REFERENCES}

1. Albers GW, Bates VE, Clark WM, Bell R, Verro P, Hamilton SA. Intravenous tissue-type plasminogen activator for treatment of acute stroke: the Standard Treatment with Alteplase to Reverse Stroke (STARS) study. JAMA. 2000 Mar 1;283(9):1145-50.

2. Breuer L, Blinzler C, Huttner HB, Kiphuth IC, Schwab S, Kohrmann M. Off-label thrombolysis for acute ischemic stroke: rate, clinical outcome and safety are influenced by the definition of 'minor stroke'. Cerebrovas Dis. 2011 Aug;32(2):177-85.

3. Brunner F, Tomandl B, Schroter A, Mellinghoff C, Haldenwanger A, Hildebrandt $\mathrm{H}$, et al. Hemorrhagic complications after systemic thrombolysis in acute stroke patients with abnormal baseline coagulation. Eur J Neurol 2011 Dec;18(12):1407-11.

4. Hacke W, Kaste M, Bluhmki E, Brozman M, Dávalos A, Guidetti D, et al. Thrombolysis with Alteplase 3 to 4.5 Hours after Acute Ischemic Stroke. N Engl J Med. 2008 Sep;359(13):1317-29.

5. Katzan IL, Furlan AJ, Lloyd LE, Frank JI, Harper DL, Hinchey JA, et al. Use of tissue-type plasminogen activator for acute ischemic stroke: the Cleveland area experience. JAMA. 2000 Mar 1;283(9):1151-8.

6. Kim J-T, Park M-S, Chang J, Lee JS, Choi K-H, Cho K-H. Proximal Arterial Occlusion in Acute Ischemic Stroke with Low NIHSS Scores Should Not Be Considered as Mild Stroke. PLOS ONE. 2013 Aug;8(8):e70996.

7. Lopez-Yunez AM, Bruno A, Williams LS, Yilmaz E, Zurrú C, Biller J. Protocol violations in communitybased rTPA stroke treatment are associated with symp- 
tomatic intracerebral hemorrhage. Stroke. 2001 Jan;32(1): 12-6.

8. Mazya M, Egido JA, Ford GA, Lees KR, Mikulik R, Toni $\mathrm{D}$, et al. Predicting the risk of symptomatic intracerebral hemorrhage in ischemic stroke treated with intravenous alteplase: safe Implementation of Treatments in Stroke (SITS) symptomatic intracerebral hemorrhage risk score. Stroke. 2012 Jun;43(6):1524-31.

9. Meretoja A, Putaala J, Tatlisumak T, Atula S, Artto V, Curtze S, et al. Off-label thrombolysis is not associated with poor outcome in patients with stroke. Stroke. 2010 Jul;41(7):1450-8.

10. Nedeltchev K, Schwegler B, Haefeli T, Brekenfeld C, Gralla J, Fischer U, et al. Outcome of stroke with mild or rapidly improving symptoms. Stroke. 2007 Sep;38(9): 2531-5.

11. Rajajee V, Kidwell C, Starkman S, Ovbiagele B, Alger JR, Villablanca P, et al. Early MRI and outcomes of untreated patients with mild or improving ischemic stroke. Neurology. 2006 Sep 26;67(6):980-4.

12. Rubiera M, Ribo M, Delgado-Mederos R, Santamarina E, Delgado P, Montaner J, et al. Tandem internal carotid artery/middle cerebral artery occlusion: an independent predictor of poor outcome after systemic thrombolysis. Stroke. 2006 Sep;37(9):2301-5.

13. Smith EE, Abdullah AR, Petkovska I, Rosenthal E, Koroshetz WJ, Schwamm LH. Poor outcomes in patients who do not receive intravenous tissue plasminogen activator because of mild or improving ischemic stroke. Stroke. 2005 Nov;36(11):2497-9.

14. Tanne D, Kasner SE, Demchuk AM, Koren-Morag N, Hanson S, Grond M, et al. Markers of increased risk of intracerebral hemorrhage after intravenous recombinant tissue plasminogen activator therapy for acute ischemic stroke in clinical practice: the Multicenter rt-PA Stroke Survey. Circulation. 2002 Apr 9;105(14):1679-85.

15. Tsivgoulis G, Saqqur M, Sharma VK, Lao AY, Hill MD, Alexandrov AV. Association of pretreatment blood pressure with tissue plasminogen activator-induced arterial recanalization in acute ischemic stroke. Stroke. 2007 Mar;38(3):961-6.

16. Wardlaw JM, Murray V, Berge E, del Zoppo G, Sandercock P, Lindley RL, et al. Recombinant tissue plasminogen activator for acute ischaemic stroke: an updated systematic review and meta-analysis. Lancet. 2012 Jun;379(9834):2364-72. 